\title{
O DESIGN DA DISCIPLINA LÍNGUA INGLESA NOS CURSOS DE LICENCIATURA DA UNIVESP: CONTRIBUIÇÕES PARA A EDUCAÇÃO A DISTÂNCIA.
}

\author{
SÃO PAULO/SP JUNHO/2018
Simone Telles Martins Ramos
- CPS e UNIVESP - simonetmramos@gmail.com
F. Katherine Asega
- St. Paul's - katherineasega@gmail.com \\ Tipo: Relato de Experiência Inovadora (EI) \\ Categoria: Métodos e Tecnologias \\ Setor Educacional: EDUCAÇÃO SUPERIOR
}

\begin{abstract}
RESUMO
Este trabalho tem por objetivo relatar a experiência de professores-autores no design da disciplina li?ngua inglesa ofertada nos cursos de Graduação em Licenciatura em Ciências Naturais e Matemática da UNIVESP (Universidade Virtual do Estado de Sa?o Paulo) como componente curricular. Em vista disso, as discusso?es presentes neste trabalho contam com o aporte teo?rico que discute os princi?pios ba?sicos do modelo para desenvolvimento de cursos de li?nguas (GRAVES, 2000); o ensino de línguas com base na abordagem comunicativa (ALMEIDA FILHO, 2000; BROWN, 1993; LARSEN-FREEMAN, 1986); para?metros para elaborac?a?o de materiais educacionais digitais (TORREZANN, BEHAR, 2009); metodologias ativas (MORAN, 2015; BONWELL; EISON, 2013) e aprendizagem baseada em problemas (ARAUJO, 2009).
\end{abstract}

Palavras-chave: Ensino superior a dista?ncia. Abordagem comunicativa. Metodologias ativas. Aprendizagem baseada em problemas. Elaborac?a?o de materiais educacionais digitais (MED).

\section{AGRADECIMENTOS}

AGRADECEMOS ÀS PROFESSORAS AUTORAS QUE FIZERAM PARTE DA EQUIPE DE LÍNGUA INGLESA DO REFERIDO CURSO E À EQUIPE DE DESIGN INSTRUCIONAL DA UNIVESP. 


\section{INTRODUÇÃo}

A ampliação da oferta de cursos superiores na modalidade a distância vem sendo impulsionada por políticas públicas de expansão, regulamentadas, por exemplo, pelo Decreto no 9.057 (BRASIL, 2017), que possibilita a oferta exclusiva de cursos de graduação e pós-graduação lato sensu em EaD sem a existência prévia de credenciamento de cursos presenciais nesse nível de ensino, e que credencia automaticamente as instituições públicas de Ensino Superior (IES) para ofertar cursos nessa modalidade. Essa ampliação de oferta de cursos superiores em EaD também pode ser evidenciada nos resultados do Censo da Educação Superior (INEP, 2016), o qual revela que no período de 2015 a 2016 a oferta de cursos nessa modalidade aumentou em $20 \%$, enquanto que cursos presenciais tiveram um decréscimo de $3,7 \%$. Os dados desse documento ainda revelam que no período de 10 anos (2006-2016) o número de ingressantes em cursos de graduação presencial subiu $22 \%$, enquanto a matrícula em cursos superiores a distância cresceu 4 vezes mais.

Se tomarmos como base os dados apresentados no último Censo (INEP, 2016), e acrescentarmos outras variáveis, como, por exemplo, possíveis impactos da ampliação de vagas com o Decreto no 9.057, baixo custo e flexibilidade de estudos em termos de horário e local, podemos inferir que a expansão dos cursos superiores na modalidade a distância poderá vir a aumentar em um ritmo ainda mais acelerado. Assim, o uso das Tecnologias Digitais da Informação e Comunicação (TDICs) como espaço para a construção do conhecimento (RAMOS, 2016) deverá ser intensificado e exigirá ações imediatas de formação contínua de professores para que as demanda de produção de cursos e de materiais educacionais digitais sejam supridas com qualidade.

Dentre as disciplinas ofertadas nos cursos de graduação, temos línguas materna e estrangeiras como componentes curriculares. O foco deste artigo está na disciplina língua inglesa ofertada nos cursos de Graduação em Licenciatura em Ciências Naturais e Matemática da Universidade Virtual do Estado de São Paulo (UNIVESP). Tendo como base a necessidade emergente do compartilhamento de práticas que possam impulsionar a formação contínua de professores para atender às necessidades do atual contexto educacional, este artigo objetiva demonstrar o design da disciplina língua inglesa nesse contexto. Apresentamos a seguir uma descrição dos cursos de Licenciatura da UNIVESP, dos parâmetros para elaboração do design da disciplina língua inglesa e de algumas conquistas.

\section{OS CURSOS DE LICENCIATURA EM CIÊNCIAS NATURAIS E MATEMÁTICA}


Os cursos de Licenciatura em Ciências Naturais e Matemática ofertados pela UNIVESP, no período de 2014 a 2018, constituíram-se a partir de um modelo pedagógico que tinha como objetivo oferecer oportunidades didáticas que pudessem estimular os estudantes para o autoconhecimento e expansão de suas capacidades e potencialidades (ARAUJO, 2009), tendo como base a Aprendizagem Baseada em Problema (PBL - Problem Based Learning). Cada curso possui uma carga-horária total de 780h, distribuídas ao longo de 4 anos, com disciplinas organizadas bimestralmente em 8 semanas letivas. Além disso, são ofertados encontros presenciais quinzenais e atividades síncronas nos Projetos Integradores.

Nesses cursos, a disciplina língua inglesa tem como principal objetivo desenvolver a competência comunicativa dos estudantes (ALMEIDA, 2000; BROWN, 1993) em contextos acadêmico-profissionais em nível de conhecimento B1 (COUNCIL OF EUROPE, 2001). A disciplina possui uma carga-horária total de 240 horas subdivididas em 12 bimestres, ofertados ao longo de 3 anos de curso. Assim, professores e alunos precisam estar engajados em situações de comunicação que priorizem a participação ativa dos alunos tanto em compreensão como produção oral e escrita.

Com base nesse cenário, a equipe de professores-autores da disciplina iniciou o design da disciplina língua inglesa utilizando como princípios básicos o modelo para desenvolvimento de cursos de línguas (GRAVES, 2000), a abordagem comunicativa para o ensino de línguas (ALMEIDA FILHO, 2000; BROWN, 1993), parâmetros para elaboração de materiais educacionais digitais (TORREZANN; BEHAR, 2009), metodologias ativas (MORAN, 2015; BONWELL, EISON, 2013) e aprendizagem baseada em problemas (ARAUJO, 2009).

\section{O DESIGN DA DISCIPLINA LÍNGUA INGLESA}

Um dos primeiros desafios encontrados pela equipe de inglês foi o design da disciplina devido à diversidade de elementos que fariam parte da proposta. Por um lado, havia uma preocupação com os princípios teóricos de ensino-aprendizagem de uma língua estrangeira que iriam nortear a proposta da disciplina, e, por outro, com o uso das TIDICs como a materialização do espaço social para o desenvolvimento de novos conhecimentos. Para tanto, a equipe estabeleceu como primeiro princípio a utilização do modelo clássico para design de cursos proposto por Graves (2000) e a utilização dos elementos essenciais para elaboração de Material Educacional Digital - MED (TORREZAN; BEHAR, 2009) como elementos que se entrelaçariam a esse modelo.

No modelo de Graves (2000), o design de um curso não é um processo linear, mas 
multifacetado que não prioriza hierarquia ou sequência fixa a ser seguida, isto é, trata-se de um conjunto de componentes que funciona como um sistema em que planejamento e escolhas fazem parte de um fluxo contínuo. A equipe utilizou os seguintes componentes como princípios norteadores: análise de necessidades; formulação dos objetivos e metas; desenvolvimento de materiais; desenho de um plano de avaliação; organização do curso e conceitualização do conteúdo; todos devidamente ancorados em dois outros elementos: o contexto, isto é, lugar, tempo e condições em que o curso ocorrerá, e as percepções da comunidade acadêmica sobre o processo de ensino-aprendizagem.

Por se tratar de um contexto de ensino-aprendizagem na modalidade a distância, a equipe foi buscar elementos que pudessem agregar o uso da tecnologia ao design do curso com o objetivo de obter uma compreensão mais detalhada sobre a disponibilidade de recursos e sua influência na tomada de decisão em relação ao design. Com base nos trabalhos de Torrezann e Behar (2009, p. 07), a equipe agregou à análise de necessidades três fatores de suporte: os técnicos, ligados à interface homem-ma?quina, usabilidade, acessibilidade, navegac?a?o e interac?a?o; os gráficos, ligados ao design e à estética; e os pedago?gicos, que se referem à aplicac?a?o das tecnologias digitais na educac?a?o. A seguir, apresentaremos os os elementos que compuseram o design da disciplina, iniciando pela análise de necessidades e os fatores de suporte.

\subsection{Análise de Necessidades}

A análise de necessidades teve como objetivo levantar as necessidades dos alunos e da instituição em relação ao uso da língua no âmbito acadêmico-profissional (GRAVES, 2000). Referente às necessidades dos alunos, a oferta da língua inglesa estava diretamente ligada ao perfil do egresso - alunos, em sua maioria, oriundos da escola pública e com idade média de 28 anos. Nesse contexto, a instituição entendia que a oferta desta disciplina na modalidade curricular poderia oportunizar o desenvolvimento de habilidades comunicativas que levassem os alunos a utilizar a língua como um grande instrumento de pesquisa e de comunicação na área de Ciências Naturais e Matemática e ensino. Os objetivos propostos pela disciplina atendiam tanto às necessidades dos alunos quanto da instituição uma vez que o ementário estabelecia como objetivo geral o desenvolvimento de habilidades comunicativas (ALMEIDA FILHO, 2000; BROWN, 1993) em contextos acadêmico-profissionais, em nível de proficiência de B1 (COUNCIL OF EUROPE, 2001), tendo como foco o desenvolvimento da oralidade enquanto principal habilidade comunicativa.

\subsection{Fatores de suporte}


Após o levantamento de necessidades, a equipe iniciou o levantamento dos recurso tecnológicos disponíveis para o ensino da língua inglesa, tomando como base os fatores de suporte propostos por Torrezann e Behar (2009): fatores técnicos, gráficos e pedagógicos. Quanto aos fatores técnicos, a equipe evidenciou que o material didático do curso seria, naquele momento de implantação, alocado em dois ambientes virtuais distintos: no Canvas e no Google Drive. O Canvas seria utilizado como um repositório dos vídeos e de textos no formato PDF e para a disponibilização de um fórum de dúvidas. O Google Drive seria utilizado com um repositório das atividades obrigatórias de cunho avaliativo. No que tange ao design e à estética, o material iria refletir a identidade visual da instituição e do público alvo, a partir de padronizações de formatação gráfica utilizadas na formatação dos materiais. Nesse contexto, a lógica de navegação do aluno (TORREZANN; BEHAR, 2009) percorria os seguintes caminhos: acesso ao AVA para assistir a videoaula da disciplina; interação opcional no fórum de dúvidas, localizado logo abaixo da videoaula; acesso aos materiais em PDF e acesso ao link dos arquivos das atividades obrigatórias armazenadas Google Drive.

Em termos pedagógicos, a oferta da disciplina língua inglesa seria totalmente assíncrona, privilegiando a relação do aluno-material didático, seguida pelas interações aluno-professor e aluno-aluno no fórum de dúvidas, uma vez que a recursividade no Canvas não estava sendo utilizada em sua potencialidade total. Quanto às atividades propostas, seriam realizadas individualmente a partir de um arquivo em word localizado no Google Drive. Para tanto, o aluno deveria baixar o arquivo, responder as questões dissertativas ou de múltipla escolha e subir o arquivo com as respostas, também no formato word, nas pastas determinadas.

Com base no exposto, foi possível evidenciar que que a metodologia PBL seria utilizada nos momentos presenciais quinzenais e nas atividades síncronas oferecidas somente pela disciplina Projeto Integrador. Já na organização dos conteúdos proposta pela instituição, os alunos de inglês não seriam submetidos a desafios que pudessem mobilizar suas competências intelectuais, emocionais, pessoais e comunicacionais (MORAN, 2015). As situações didáticas de inglês não promoveriam atividades em pares e/ou em grupos uma vez que essas seriam executadas individualmente, em arquivos de word armazenados no Google Drive. A estrutura tecnológica que estava à disposição trazia para equipe de inglês um grande desafio a ser vencido: o desenvolvimento de habilidades comunicativas que pudessem ser inseridas de forma interdisciplinar no Projeto Integrador.

\subsection{Formulação dos objetivos e metas}


Depois de ter uma visão ampla a partir do levantamento de necessidades e dos fatores de suporte, a equipe reuniu os dados obtidos e contrastou-os com os objetivos propostos pelas ementas da disciplina. Considerando que as ementas estavam embasadas na abordagem comunicativa para o ensino de línguas (ALMEIDA FILHO, 2000; BROWN, 1993), a equipe selecionou as principais características dessa abordagem com o objetivo para trazer para o design da disciplina uma aprendizagem mediada por tecnologias digitais (RAMOS, 2016), centrada no aluno e não no conteúdo.

Essa seleção resultou em uma guia com 7 princípios básicos que foram utilizados no design do curso: 1) organização do processo de ensino-aprendizagem a partir de atividades e tarefas que pudessem ser de real interesse dos alunos do curso (BROWN, 1993); 2) uso da língua inglesa como ferramenta de comunicação no processo de ensinoaprendizagem (BROWN, 1993) e da língua portuguesa como apoio (ALMEIDA FILHO, 2000); 3) uso de textos autênticos (BROWN, 1993), respeitando o nível de conhecimento proposto pelas ementas (COUNCIL OF EUROPE, 2001); 4) ensino de aspectos culturais da língua inglesa (BROWN, 1993); 5) criação de contextos que fomentem o uso da língua além da sala de aula a partir da experiência profissional dos alunos (BROWN, 1993); 6) apresentação das situações de aprendizagem em forma de problematização tendo como base temas que permeiam o universo acadêmico dos alunos e prática didática (ARAUJO, 2009), e 7) atenção aos diferentes estilos de aprendizagem (ALMEIDA FILHO, 2000) a partir do uso de diferentes tipologias de atividades e de ferramentas tecnológicas.

A equipe compreendeu que o MED de inglês deveria ser diferente dos materiais das demais disciplinas. O princípio básico dssa tomada de decisão foi o fato de que o ensino de uma língua estrangeira com foco na abordagem comunicativa demandava não somente um uso diferenciado das tecnologias digitais disponíveis, mas também um design renovado para a apresentação dos conteúdos. A equipe almejava um design que trouxesse à tona a construção de uma narrativa que conduzisse o aluno por uma trilha de aprendizagem (FREITAS; BRANDÃO, 2006) que resultasse no desenvolvimento das competências comunicativas determinadas pelas ementas da disciplina. Com base nesses objetivos e metas, a equipe desenvolveu o material e organizou o curso.

\subsection{Desenvolvimento dos materiais e organização do curso}

Com a autorização da UNIVESP, a equipe de inglês iniciou um projeto piloto da disciplina considerando que o processo de ensino-aprendizagem seria organizado a partir de atividades e tarefas que fossem de real interesse dos alunos (BROWN, 1993). A situações de aprendizagem seriam apresentadas em forma de problematização 
(ARAUJO, 2009), priorizando interações aluno-professor, aluno-aluno e aluno-material em dinâmicas que pudessem permitir o trabalho e a avaliação individual, em pares ou em grupos. Isso demandaria o uso mais efetivo das potencialidades do Canvas a partir uso de ferramentas tecnológicas diversas que facilitassem a elaboração de diferentes tipologias de atividades e o uso de textos autênticos (ALMEIDA FILHO, 2000).

O objetivo da equipe era testar novas possibilidades, sem fugir ao padrão estabelecido pela instituição, portanto, o padrão de conteúdo seria mantido: videoaulas com fórum de dúvidas, material de leitura e entrega das atividades obrigatórias de cunho avaliativo . $O$ que mudaria de fato seria a lógica de navegação, pois o aluno acessaria o AVA para percorrer seu itinerário formativo e faria um conjunto maior de atividades para privilegiar a interação em detrimento da exposição de conteúdo. Devido a isso, a equipe decidiu organizar o MED em duas trilhas de aprendizagem: uma trilha que organiza o conteúdo da aula em si e que oferece ao aluno possibilidades de escolha e a trilha do curso com o conteúdo dos 12 bimestres letivos organizados em uma narrativa que fomenta o uso da língua a partir da experiência acadêmico-profissional dos alunos (FREITAS; BRANDÃO, 2006), como segue:

- Inglês para Fins Acadêmicos (bim. 1, 2, 3 e 4). Nesses bimestres, o aluno inicia um trabalho com foco no desenvolvimento das habilidades de compreensão escrita e oral e produção escrita em contextos acadêmicos, pois seu objetivo principal é buscar conhecimento em artigos, aulas e vídeos de instituições internacionais como fonte de pesquisa.

- Congresso Internacional (bim. 5, 6, 7). A partir desses bimestres, o aluno passa a utilizar as habilidades de compreensão e produção oral e escrita, pois ele participa de um congresso internacional na área de STEM (Science, Technology and Mathematics) para apresentar os resultados de seu projeto integrador. Para isso, o aluno é exposto a situações rotineiras de grandes eventos como credenciamento no congresso, participação em comunicações, apresentação de pôsteres, entre outros.

- Graduação sanduíche (bim. 8, 9 e 10). Nesses bimestres, o aluno inicia uma nova jornada: a possibilidade de fazer graduação sanduíche em uma universidade americana. Para tanto, ele recebe uma bolsa de estudos e experimenta situações diversas como entrevista na alfândega, reuniões com professores da universidade, estágio como professor assistente de aula em uma escola americana, entre outros. 
- Retorno ao Brasil (bim. 11 e 12). Nestes últimos bimestres, o aluno se prepara para voltar ao Brasil e é exposto à situações como mudança de horário de vôo, longas esperas no Aeroporto, entre outros.

$\mathrm{Na}$ trilha da aula, os itinerários formativos foram subdivididos em 7 aulas de conteúdo e 1 aula de avaliação presencial, roteirizados com a seguinte estrutura: apresentação do contexto da aula recapitulando a situação de aprendizagem da aula anterior e iniciando a contextualização da atual; estrutura da aula com apresentação dos recursos disponíveis; objetivos de aprendizagem; desafio a ser resolvido a partir de atividade de prática; sugestão de percursos para vencer o desafio; vocabulário da aula; apresentação de situações de situações de aprendizagem, intercalando novo conteúdo com atividades de prática e vice-versa; dicas culturais; para saber mais por meio do acesso a links com atividades extras e outras informações; encerramento da aula com resumo dos objetivos de aprendizagem e introdução ao tema da aula seguinte.

A cada aula o aluno foi submetido a um desafio que tinha como objetivo articular os conteúdos da temática apresentada e motivar a participação do aluno a partir da realização de uma tarefa mais complexa que envolvia possibilidades de escolha e tomada de decisão. Devido a algumas restrições relacionadas aos fatores de suporte (TORREZANN; BEHAR, 2009), a navegabilidade entre os conteúdos que auxiliam na resolução do desafio teve que se manter de forma sequencial e linear. A despeito disso, a equipe apresentou aos alunos um mapa ilustrado com possibilidades de navegação, deixando claro que tinham liberdade para escolher e trilhar seus itinerários para resolver o desafio proposto.

Com relação às avaliações, a UNIVESP propunha uma atividade denominada Portfólio, contendo atividades similares às oferecidas nos módulos. O Portfólio era feito de modo assíncrono e submetido via plataforma. No entanto, com o objetivo de aumentar a interação entre os alunos e promover maior exposição à língua, a equipe de Inglês optou por oferecer atividades de listening e speaking nas quais os alunos, utilizando diversos recursos digitais, avaliavam uns aos outros, tendo como parâmetro de julgamento a inteligibilidade, ou seja, o quanto a mensagem era compreensível ou não para o interlocutor. Além disso, ao chegar na sétima aula, o design oferecia uma autoavaliação com base na qual o aluno era levado a revisitar os conceitos das aulas anteriores com o objetivo de identificar os conteúdos que ainda precisavam de mais atenção e prática.

\section{CONSIDERAÇÕES FINAIS}

O design da disciplina Língua Inglesa nos cursos de Licenciatura da UNIVESP foi um 
desafio que a equipe de língua inglesa venceu. Para iniciar o trabalho na instituição, a equipe trabalhou intensamente com pesquisa e um dos objetivos iniciais era saber mais sobre metodologias ativas, aprendizagem baseada em problemas, o ensino comunicativo e possibilidades de materiarizá-lo na modalidade a distância (TORREZANN; BEHAR, 2009), entre outros.

No decorrer da pesquisa, a equipe evidenciou que as teorias de ensino-aprendizagem que embasavam o ementário da disciplina correlacionavam-se ao trabalho que estava sendo feito na UNIVESP, isto é, o foco estaria na aprendizagem e não no ensino. $O$ resultado, portanto, poderia ser obtido com a resolução de um desafio que integraria as habilidades de aprendizagem e de trabalho em equipe e mobilizaria pensamento crítico e criativo (ARAUJO, 2009).

A partir dessa compreensão, a equipe buscou o apoio da UNIVESP para iniciar o projeto piloto que serviu de inspiração para demais disciplinas ofertadas na instituição. Atualmente, as demais disciplinas fazem uso da potencialidade do Canvas com base no design proposto pela disciplina língua inglesa. $O$ itinerário formativo é muito similar ao do inglês, as atividades ofertadas são dinâmicas e possuem uma editoração em formatos que de fato inserem o aluno como protagonista no processo de ensino-aprendizagem.

A disciplina de inglês continua sendo ofertada, mas em outro contexto, no Curso Superior de Tecnologia em Gestão Pública da Fatec (Faculdade de Tecnologia) em parceria com a UNIVESP. Atualmente, a equipe enfrenta novos desafios, o foco agora está no mercado de trabalho, em novas trilhas de aprendizagem, em tipologias de atividades com recursos tecnológicos mais interativos, mapeamento da avaliação com base em competência, aprendizagem de inglês em e por games massivos (ASEGA, 2015) e possibilidades de gamificação.

\section{REFERÊNCIAS}

ALMEIDA FILHO, J. C. P. de. Dimensões comunicativas no ensino de línguas. Campinas, SP: Pontes, 1993.

ARAÚJO, U. F. Aprendizagem baseada em problemas no ensino superior. São Paulo: Summus, 2009.

ASEGA, F. K. Avaliando as potencialidades de um game para o ensino e a aprendizagem de língua inglesa.125f. Dissertação (Mestrado em Linguística Aplicada) Pontifícia Universidade Católica de São Paulo (PUC-SP), São Paulo, São Paulo. 2015. 
BONWELL, C. C.; EISON, J. A. Active learning: creating excitement in the classroom. Washington, DC: Eric Digests, 1991. Publication Identifier ED340272.

BRASIL. Decreto $n^{\circ}$ 9.057, de 25 de maio de 2017. Regulamenta 0 art. 80 da Lei no 9.394, de 20 de dezembro de 1996.

BROWN, H. D. Principles of Language Learning and Teaching. 4. ed. New York: Longman, 2000.

COUNCIL OF EUROPE. Common European framework of references for languages: learning, teaching, assessment. Strasbourg: Cambridge University Press (CUP), 2001.

FREITAS, I. A.; BRANDA?O, H. P. Trilhas de aprendizagem como estrate?gia de TD\&E. In: BORGES-ANDRADE, J. E.; ABBAD, G. S.; MOURA?O, L. (Org.). Treinamento, desenvolvimento e educac?a?o em organizac?o?es e trabalho: fundamentos para a gesta?o de pessoas. Porto Alegre: Artmed/Bookman, 2006. p. 97-113.

GRAVES, K. (2000). Designing Language Courses: a guide for teachers. Boston MA: Heinle Cengage.

INEP. Censo Escolar da Educação Superior 2009. Brasília, DF: Ministério da Educação/ Inst. Nacional de Estudos e Pesquisas Educacionais Anísio Teixeira, 2009.

MORÁN, J.. Mudando a educação com metodologias ativas. In: SOUZA, C. A.; MORALES, O. E. T. (Orgs.). Coleção Mídias Contemporâneas. Convergências Midiáticas, Educação e Cidadania: aproximações jovens. Vol. II. PG: Foca FotoPROEX/UEPG, 2015.

RAMOS, S. T. M. Contribuições do curso Elaboração de Material Educacional Digital - Nível básico para o letramento digital de professores de inglês. $186 \mathrm{f}$. Tese (Doutorado em Linguística Aplicada) - Pontifícia Universidade Católica de São Paulo (PUC-SP), São Paulo, São Paulo. 2016.

TORREZANN, C.A.W.; BEHAR, P.A. Parâmetros para a construção de materiais educacionais digitais do ponto de vista do design pedagógico. In: BEHAR, P. (org.). Modelos Pedagógicos em Educação a Distância. Porto Alegre, Artmed, 2009. 